\title{
Fetal atrioventricular and outflow tract flow velocity waveforms during conducted and blocked supraventricular extrasystoles
}

\author{
K. van der Mooren, J. W. Wladimiroff and Th. Stijnen*
}

Department of Obstetrics and Gynccology and *Department of Biostatics, Academic Hospital Rotterdam-Dijkzigt, Erasmus University Rotterdam, Rotterdam, The Netherlands

Key words: Fetal Cardiac Flow Velocities, Doppler Ultrasound, Extrasystoles

\begin{abstract}
Maximum flow velocity waveforms at atrioventricular and outflow tract level were studied cross-sectionally in 19 human fetuses with conducted and/or blocked supraventricular extrasystoles ranging from 25 to 38 weeks of gestation. At outflow tract level, peak systolic velocity and acceleration time for extrasystolic and post-extrasystolic beats were compared with those for the immediately preceding normal beat. Regression lines were calculated for peak systolic velocities with filling time. At atrioventricular level, peak-E wave and peak-A wave velocities and E/A ratio for the extrasystolic and post-extrasystolic beats were compared with those for the normal beat. At all levels, time-averaged velocities were compared with reference charts standardized for gestational age.

Peak systolic velocity and acceleration time during the post-extrasystolic beat were higher than during the normal beat; the Frank-Starling mechanism, post-extrasystolic potentiation as well as reduced ventricular afterload may all play a role in this. At all measuring levels, time-averaged velocity during the extrasystolic beat was strikingly lower than the reference velocities. It is postulated that the increased blood volume and contraction force during the post-extrasystolic beat cause the valve area to become larger, resulting in a relative decrease in velocities measured by Doppler ultrasound.
\end{abstract}

\section{INTRODUCTION}

Supraventricular extrasystolic beats, conducted or blocked, are one of the most frequent forms of fetal arrhythmias encountered ${ }^{1.2}$. They do not seem to have any negative circulatory effects, provided that there are no associated structural anomalies ${ }^{2,3}$. This association is reported to occur in about $5 \%$ of cases $^{3}$. Some authors state that extrasystoles may be indicative of fetal distress during labor in some instances ${ }^{2,4}$. Premature beats are, however, found in $1 \%$ of healthy neonates ${ }^{5}$ and in up to $10 \%$ of normal fetuses'.

The hemodynamics of the human fetal cardiovascular system can be studied non-invasively and semi-quantitively by means of Doppler ultrasound techniques. In the human fetus, Doppler echocardiography can be performed from about 11 weeks of gestation onwards ${ }^{6}$. To our knowledge, a detailed analysis of the Doppler flow velocity waveforms from outflow tracts and atrioventricular valves has never been performed in a large series of fetuses with supraventricular extrasystolic beats.

In this study we addressed the following questions:

(1) In which ways do flow velocity waveforms from outflow tracts and atrioventricular valves change during blocked and during conducted supraventricular extrasystoles, when compared to waveforms obtained from normal sinus beats?

(2) Is there a relation between these waveform changes and the preceding beat-to-beat interval?

\section{MATERIAL AND METHODS}

The study group consisted of 17 women, who were referred between November 1988 and May 1989 because of an irregular fetal heart rhythm which was noticed during a routine obstetrical examination. The type of arrhythmia was established by means of M-mode echocardiography ${ }^{3}$. Ten women showed fetal conducted supraventricular extrasystoles (Group 1), whereas five women displayed fetal blocked supraventricular extrasystoles (Group 2). Two women demonstrated both types, and were therefore included in both groups. Group 1 eventually consisted of 12 , and Group 2 of seven women. In all instances, extrasystoles occurred at least once in every 10 beats. All women gave informed consent to

Correspondence: Professor J. W. Wladimiroff, Department of Obstetrics and Gynecology, Academic Hospital Rotterdam-Dijkzigt, Erasmus University Rotterdam, Dr. Molewaterplein 40, 3015 GD Rotterdam, The Netherlands 
participate in the study. The study protocol was approved by the Hospital Fthics Committee.

The pregnancy duration was determined from the last menstrual period and confirmed by ultrasonic measurements of the biparietal diameter between 14 and 18 weeks' gestation. Before a Doppler study was performed, fetal structural anomalies and signs of fetal cardiac decompensation were excluded by means of a detailed sonographic cxamination. All pregnancies were uneventful, and birth weights were between the 5th and 95th percentiles according to Kloosterman's tables, corrected for maternal parity and fetal sex?

The mean maternal age in Group 1 was 28.4 years (range $23-33$ years), the median parity was 0 (range $0-2$ ), and the mean gestational age was 34.2 weeks (range 27.0-38.3 weeks). The mean maternal age in Group 2 was 26.9 years (range 23-30 years), the median parity was 0 (range $0-5$ ) and the mean gestational age was 30.2 weeks (range 25.3-36.0 weeks).

Reference charts obtained in a previous study on normal cardiac flow velocity waveforms ${ }^{8}$ were used for comparison of time-averaged velocity between supraventricular cxtrasystolcs and normal (sinus) bcats.

A combined mechanical sector scanner and pulsed Doppler system (Diasonics CV 400) with carrier frequencies of 3.5 and $3.0 \mathrm{MHz}$ was used for blood flow velocity measurements in the ascending aorta, pulmonary artery, and at the mitral and tricuspid valves. The sector scanner operates at power outputs less than $100 \mathrm{~mW} / \mathrm{cm}^{2}$ spatial peak/temporal average in both imaging and Doppler modes by manufacturer's specifications. Two-dimensional imaging was used to ensure the correct position of the pulsed Doppler gate before and after each Doppler tracing was obtained. Maximum flow velocity waveforms from the ascending aorta were recorded from the 'fivechamber vicw'. Maximum flow velocity waveforms from the pulmonary artery were collected from the conventional short-axis view. Maximum flow velocity waveforms at mitral and tricuspid valve levels were recorded from the four-chamber view. At all sites, the Doppler sample volume was placed immediately distal to the valve leaflets. The Doppler sample volume length ranged between 0.1 and $0.4 \mathrm{~cm}$. Doppler tracings were accepted when the angle between the Doppler cursor and the assumed direction of flow was $10^{\circ}$ or less, and when, after completion of a Doppler recording, the Doppler cursor and sample volume were still correctly positioned. Doppler studies were performed by one examiner (K.v.d.M.). All blood flow velocity waveforms were obtained during fetal apnea and stored on videotape. From hard copies the analysis of at lcast 36 consccutive waveforms from each site was carried out using a microcomputer (Olivetti 240) linked to a graphics tablet. The following parameters were calculated in the two outflow tracts and at the atrioventricular level.

\section{Outflow tracts}

(1) Conducted supraventricular extrasystoles: peak systolic velocity $(\mathrm{cm} / \mathrm{s})$ and acceleration time (ms) for sequences consisting of the normal beat immediately preceding the extrasystolic beat, the extrasystolic heat and the post-extrasystolic beat;

(2) Blocked supraventricular extrasystoles: peak systolic velocity $(\mathrm{cm} / \mathrm{s})$ and acceleration time $(\mathrm{ms})$ for sequences consisting of the normal beat and the post-extrasystolic beat;

(3) Finally, the time-averaged velocity from each whole Doppler tracing was calculated in all patients.

\section{Atrioventricular level}

(1) Conducted supraventricular extrasystoles: peak-E wave and peak-A wave velocities $(\mathrm{cm} / \mathrm{s})$ and $\mathrm{E} / \mathrm{A}$ ratios for sequences consisting of the normal beat immediately preceding the extrasystolic beat, the extrasystolic beat and the post-extrasystolic beat; for the extrasystolic beat only peak-A wave velocity was calculated;

(2) Blocked supraventricular extrasystoles: peak-E wave and peak-A wave velocities and E/A ratios for sequences consisting of the normal beat and the post-extrasystolic beat;

(3) Finally, the time-averaged velocity from each whole Doppler tracing was calculated in all patients.

Sequences were only included if at least three sinus beats preceded a particular extrasystolic beat, to exclude possible influence from a previous extrasystole on the normal beat. In 15 fetuses, comparisons were made at outflow tract level not only for the post-extrasystolic beat, but also for the sinus beat immediately following this beat and the normal bcat. This was done because in animal laboratory experiments a gradual decay of postextrasystolic potentiation over some beats has been described ${ }^{9}$.

Time intervals (ms) preceding and following a particular beat were calculated. The former is referred to as filling time, the latter as period time relative to a particular flow velocity waveform. In Figure 1, these time intervals are presented in a schematic example of a conducted supraventricular extrasystole at outflow tract level.

Peak systolic velocities were measured from the zeroline to the highest point of the Doppler velocity peak. Acceleration time was measured as the time between the onset of ejection and the peak of velocity. Time-averaged vclocity was calculated as area-under-curve divided by period time.

$\Lambda \mathrm{ll}$ Doppler studies were performed $2 \mathrm{~h}$ following breakfast or lunch with the patient in a semi-recumbent position. The duration of one examination never exceeded $45 \mathrm{~min}$

Statistical analysis consisted of the following items:

(1) For each 'sequence' consisting of: normal beat-extrasystolic beat-post-extrasystolic beat, paired 


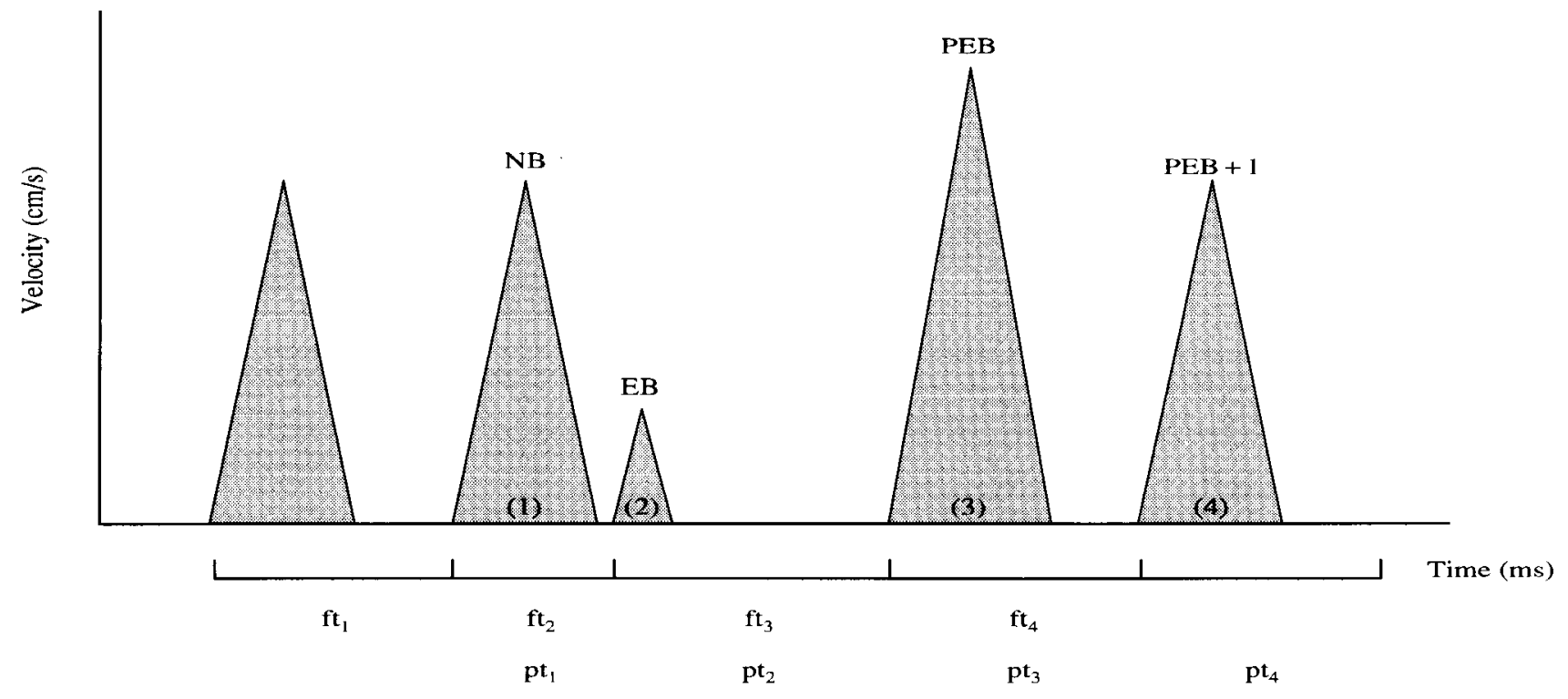

Figure 1 Schematic representation of the different time intervals in a sequence with a conducted supraventricular extrasystole at outflow tract level. $\mathrm{NB}=$ normal beat, the first beat of a sequence; $\mathrm{EB}=$ extrasystolic beat, the second beat of a sequence; PEB = post-extrasystolic beat, the third beat of a sequence; PEB $+1=$ the first beat following a PEB, the fourth beat of a sequence; $\mathrm{ft}_{i}=$ filling time belonging to beat number $i ; \mathrm{pt}_{i}=$ period time belonging to beat number $i$, where $i$ takes any value from 1 to 4

analysis was performed, by means of the $t$-test, of the above-mentioned parameters for extrasystolic versus normal beat and for post-extrasystolic versus normal beat, and the relative differences were calculated as percentages. Also, the sinus beat following the post-extrasystolic beat was compared with the normal beat by means of the paired Student's $t$-test.

(2) Al all four measuring sites, mean time-averaged velocity during supraventricular extrasystoles was compared with the mean time-averaged velocity established in an carlier study standardized for gestational age ${ }^{8}$. This was done as follows: for the mean time-averaged velocity obtained in each woman in the present study, the standard deviation score (SDS) relative to the reference value was calculated. The standard deviation score is the difference of the calculated and the reference mean divided by the standard deviation (SD) of the reference population at a particular gestational age. The SDS of a particular patient measures the distance of the value of the patient to the reference mean in standard deviation units. Then a one-sample $t$-test was used to test whether the mean SDS differed significantly from zero.

(3) At outflow tract level, the regression lines of filling time with peak systolic velocities for extrasystolic, normal and post-extrasystolic beats, both combined and separately, were established for each woman. Then a one-sample $t$-test was used to test whether the mean slope of these regression lines differed significantly from zero. Also, the relationship of extrasystolic filling time with peak systolic velocity for the post-extrasystolic beats was established. The level of statistical significance was set at 0.05 .

\section{RESULTS}

Good quality Doppler registrations were obtained in each instance at all sites. In four women, a second recording was necessary due to an unfavorable fetal position during the first recording. The time interval between these two recordings never exceeded $30 \mathrm{~min}$. The average number of cycles studied per patient during supraventricular extrasystoles was 29.1 (SD 10.2) for the pulmonary artery, 29.5 (SD 10.2) for the ascending aorta, 29.3 (SD 10.1) for the mitral valve and 26.9 (SD 8.1) for the tricuspid valve. In total, 2182 cycles were collected.

\section{Group $1(n=12)$}

\section{Outflow tract level}

All parameters obtained showed significant differences for extrasystolic versus normal beats and for postextrasystolic versus normal beats (Table 1). Particularly, the peak systolic velocities in the pulmonary artery and ascending aorta were always higher in post-extrasystolic than in normal beats. The mean extrasystolic filling time was $331 \mathrm{~ms}$ (SD 28), the mean post-extrasystolic filling time was $456 \mathrm{~ms}$ (SD 54), and the mean reference filling time was $435 \mathrm{~ms}$ (SD 25). These differences were all statistically significant $(p<0.001)$.

\section{Atrioventricular level}

The peak-E wave velocity for post-extrasystolic beats did not differ from peak-F wave velocity for normal beats. The peak-A wave velocity for post-extrasystolic beats was lower than for normal beats. Correspondingly, E/A ratios at both levels increased during post-extrasystolic beats. The peak-A wave velocity for extrasystoles was 
Table 1 Mean relative differences (in \%) of peak systolic velocity $(\mathrm{cm} / \mathrm{s})$ and acceleration time $(\mathrm{ms})$ for extrasystolic and post-extrasystolic beats compared with normal beats at all four measuring sites for conducted supraventricular extrasystoles (Group 1)

\begin{tabular}{|c|c|c|c|c|}
\hline & Mean & $\begin{array}{l}\text { Standard } \\
\text { deviation }\end{array}$ & Range & $p$ value \\
\hline \multicolumn{5}{|c|}{ Pulmonary artery peak systolic velocity } \\
\hline $\begin{array}{l}\mathrm{EB} \\
\mathrm{PEB}\end{array}$ & $\begin{array}{r}-26.4 \\
12.5\end{array}$ & $\begin{array}{r}12.4 \\
2.9\end{array}$ & $\begin{array}{c}-51--14 \\
6-23\end{array}$ & $\begin{array}{l}<0.001 \\
<0.001\end{array}$ \\
\hline \multicolumn{5}{|c|}{ Pulmonary artery acceleration time } \\
\hline $\begin{array}{l}\text { EB } \\
\text { PEB }\end{array}$ & $\begin{array}{r}-36.0 \\
22.3\end{array}$ & $\begin{array}{r}10.3 \\
6.4\end{array}$ & $\begin{array}{c}-53--27 \\
12-30\end{array}$ & $\begin{array}{l}<0.001 \\
<0.001\end{array}$ \\
\hline \multicolumn{5}{|c|}{ Ascending aorta peak systolic velocity } \\
\hline $\begin{array}{l}\text { EB } \\
\text { PEB }\end{array}$ & $\begin{array}{r}-26.4 \\
12.0\end{array}$ & $\begin{array}{r}16.5 \\
3.7\end{array}$ & $\begin{array}{c}53-10 \\
8-16\end{array}$ & $\begin{array}{l}<0.001 \\
<0.001\end{array}$ \\
\hline \multicolumn{5}{|c|}{ Ascending aorta acceleration time } \\
\hline $\begin{array}{l}\text { EB } \\
\text { PEB }\end{array}$ & $\begin{array}{r}-32.7 \\
16.6\end{array}$ & $\begin{array}{l}8.8 \\
4.3\end{array}$ & $\begin{array}{c}-45--20 \\
8-21\end{array}$ & $\begin{array}{l}<0.001 \\
<0.001\end{array}$ \\
\hline \multicolumn{5}{|c|}{ Mitral valve peak-E wave } \\
\hline PEB & -1.2 & 14.4 & $-26-0$ & 0.77 \\
\hline \multicolumn{5}{|c|}{ Mitral valve peak-A wave } \\
\hline $\begin{array}{l}\text { EB } \\
\text { PEB }\end{array}$ & $\begin{array}{l}-18.2 \\
-15.6\end{array}$ & $\begin{array}{l}28.5 \\
10.1\end{array}$ & $\begin{array}{l}-69-20 \\
-31-0\end{array}$ & $\begin{array}{c}0.051 \\
<0.001\end{array}$ \\
\hline \multicolumn{5}{|c|}{ Mitral valve $\mathrm{E} / \mathrm{A}$ ratio } \\
\hline PEB & 14.9 & 19.5 & $0-51$ & 0.03 \\
\hline \multicolumn{5}{|c|}{ I'ricuspid valve peak-E wave } \\
\hline PEB & -0.01 & 6.7 & $-4.6-3.7$ & 0.7 \\
\hline \multicolumn{5}{|c|}{ Tricuspid valve peak-A wave } \\
\hline $\begin{array}{l}\text { EB } \\
\text { PEB }\end{array}$ & $\begin{array}{l}-33.2 \\
-20.4\end{array}$ & $\begin{array}{r}21.1 \\
7.3\end{array}$ & $\begin{array}{l}-60-0 \\
-31--10\end{array}$ & $\begin{array}{l}<0.001 \\
<0.001\end{array}$ \\
\hline \multicolumn{5}{|c|}{ Tricuspid valve E/A ratio } \\
\hline PEB & 27.5 & 19.6 & $0-57$ & $<0.01$ \\
\hline
\end{tabular}

$\mathrm{EB}=$ extrasystolic beat; $\mathrm{PEB}=$ post-extrasystolic beat

lower than for normal beats at tricuspid level, and was not different from normal beats at mitral level (Table 1).

\section{Group $2(n=7)$}

\section{Outflow tract level}

The parameters obtained showed significant differences for post-extrasystolic versus normal beats in all women (Table 2). The peak systolic velocity in the pulmonary artery and the ascending aorta was always higher in post-extrasystolic than in normal beats. The mean postextrasystolic filling time was $715 \mathrm{~ms}$ (SD 42), whereas the mean reference filling time was $474 \mathrm{~ms}$ (SD 35). This difference was also statistically significant $(p<0.001)$.

\section{Atrioventricular level}

At mitral level, peak-E wave velocities for post-extrasystolic beats were lower than peak-E wave velocities for normal beats, whereas at tricuspid level there was no difference. Peak-A wave velocities were lower for postextrasystolic than for normal beats at both sites. E/A
Table 2 Mean relative differences (in \%) of peak systolic velocity $(\mathrm{cm} / \mathrm{s})$ and acceleration time (ms) for post-extrasystolic beats compared with normal beats at all four measuring sites for blocked supraventricular extrasystoles (Group 2)

\begin{tabular}{|c|c|c|c|c|}
\hline Post-extrasystolic beat & Mean & $\begin{array}{l}\text { Standard } \\
\text { deviation }\end{array}$ & Range & $p$ value \\
\hline $\begin{array}{l}\text { Pulmonary artery } \\
\text { peak systolic velocity } \\
\text { acceleration time }\end{array}$ & $\begin{array}{l}13.9 \\
31.7\end{array}$ & $\begin{array}{l}4.4 \\
9.7\end{array}$ & $\begin{array}{l}10-24 \\
17-36\end{array}$ & $\begin{array}{l}<0.001 \\
<0.001\end{array}$ \\
\hline $\begin{array}{l}\text { Ascending aorta } \\
\text { peak systolic velocity } \\
\text { acceleration time }\end{array}$ & $\begin{array}{l}12.3 \\
18.0\end{array}$ & $\begin{array}{l}4.4 \\
7.5\end{array}$ & $\begin{array}{l}8-18 \\
025\end{array}$ & $\begin{array}{l}<0.001 \\
<0.001\end{array}$ \\
\hline $\begin{array}{l}\text { Mitral valve } \\
\text { peak E-wave } \\
\text { peak A-wave } \\
\text { E/A ratio }\end{array}$ & $\begin{array}{r}7.0 \\
-15.1 \\
13.8\end{array}$ & $\begin{array}{r}5.7 \\
8.3 \\
11.1\end{array}$ & $\begin{array}{r}-20-0 \\
-25-0 \\
0-30\end{array}$ & $\begin{array}{l}<0.02 \\
<0.005 \\
<0.02\end{array}$ \\
\hline $\begin{array}{l}\text { Tricuspid valve } \\
\text { peak E-wave } \\
\text { peak A-wave } \\
\text { E/A ratio }\end{array}$ & $\begin{array}{r}-6.7 \\
-29.5 \\
37.7\end{array}$ & $\begin{array}{r}12.7 \\
9.3 \\
27.3\end{array}$ & $\begin{array}{r}-25-11 \\
-42-17 \\
6-94\end{array}$ & $\begin{aligned} & 0.214 \\
< & 0.001 \\
< & 0.02\end{aligned}$ \\
\hline
\end{tabular}

ratios for post-extrasystolic beats were higher than for normal beats in all cases (Table 2).

For both Groups 1 and 2, none of the documented differences relative to normal beats were relatcd to gestational age.

In 15 fetuses in which at outflow tract level the first sinus beat following a post-extrasystolic beat was compared with the corresponding normal beat, no differences could be established for either peak systolic velocity or acceleration time.

At all four recording sites, the time-averaged velocities recorded during conducted and blocked supraventricular extrasystoles were strikingly lower than time-averaged velocities obtained during sinus rhythm in the controls (Tables 3-6). The vast majority of the time-averaged velocities is smaller than the lower $2.5 \%$ reference limit (i.e. SDS $<-1.96$ ). Table 7 presents, for Group 1 at pulmonary artery and ascending aorta lcvel, regression cocfficients for peak systolic velocity with filling time as well as the mean regression coefficients for all women. These regression coefficients were highly significant. In all three subgroups consisting of extrasystolic beats, normal beats and post-extrasystolic beats, the regression lines for peak systolic velocity with filling time were not significant. There was also no correlation between extrasystolic filling time and peak systolic velocity for postextrasystolic beats.

\section{DISCUSSION}

Cardiac function is gencrally described in terms of preload, inotropic state, heart rate and afterload. Preload or diastolic muscle fiber length forms the basis of the Frank-Starling mechanism. However, another important cardiac muscle property, the force-interval relationship, has been identified both in the animal and in the human adult heart ${ }^{9}$. This mechanism becomes apparent 
Table 3 Mean time-averaged velocity $(\mathrm{cm} / \mathrm{s})$ in conducted supraventricular extrasystoles (Group 1) and normal control values (mean $\pm 1 S D$ ) relative to gestational age (weeks) for pulmonary artery and ascending aorta with individual and mean (SD) standard deviation score (SDS)

\begin{tabular}{|c|c|c|c|c|c|c|}
\hline \multirow[b]{3}{*}{$\begin{array}{l}\text { Gestational } \\
\text { age (weeks) }\end{array}$} & \multicolumn{3}{|c|}{ Pulmonary artery } & \multicolumn{3}{|c|}{ Ascending aorta } \\
\hline & \multicolumn{3}{|c|}{ Time-averaged velocity } & \multicolumn{2}{|c|}{ Time-averaged velocity } & \\
\hline & Mean & $\begin{array}{c}\text { Reference } \\
\text { mean }(S D)\end{array}$ & $S D S$ & Mean & $\begin{array}{c}\text { Reference } \\
\text { mean }(S D)\end{array}$ & $S D S$ \\
\hline 27.0 & 17.1 & $22.6(1.7)$ & -3.24 & 22.1 & $26.6(2.1)$ & -2.14 \\
\hline 29.4 & 17.8 & $24.4(1.8)$ & -3.67 & 23.2 & $27.8(2.4)$ & -1.92 \\
\hline 31.5 & 18.0 & $25.1(1.9)$ & -3.55 & 19.4 & $28.8(2.7)$ & -3.48 \\
\hline 33.0 & 20.8 & $25.8(2.0)$ & -2.50 & 19.4 & $29.4(2.8)$ & -3.57 \\
\hline 34.0 & 25.9 & $26.3(2.1)$ & 0.19 & 24.6 & $29.8(3.0)$ & -1.73 \\
\hline 34.2 & 22.0 & $26.5(2.1)$ & -2.14 & 20.4 & $30.0(3.0)$ & -3.20 \\
\hline 35.2 & 19.7 & $27.0(2.2)$ & -3.32 & 21.1 & $30.4(3.1)$ & -3.00 \\
\hline 35.4 & 20.9 & $27.2(2.2)$ & -2.86 & 21.7 & $30.6(3.1)$ & 2.87 \\
\hline 36.0 & 18.5 & $27.4(2.3)$ & -3.87 & 21.1 & $30.7(3.2)$ & -3.00 \\
\hline 37.6 & 21.4 & $28.2(2.4)$ & -2.83 & 22.7 & $31.5(3.4)$ & -2.59 \\
\hline 38.0 & 18.7 & $28.4(2.5)$ & -3.88 & 25.5 & $31.6(3.4)$ & -1.79 \\
\hline 38.3 & 19.9 & $28.6(2.5)$ & -3.48 & 22.7 & $31.8(3.5)$ & -2.60 \\
\hline
\end{tabular}

Mcan SDS (SD): $-2.96(1.03)^{*} ;$ mean SDS (SD): $-2.66(0.64)^{*}$ ${ }^{*} p<0.01$

Table 4 Mean time-averaged velocity $(\mathrm{cm} / \mathrm{s})$ in conducted supraventricular extrasystoles (Group 1) and normal control values (mean $\pm 1 S D$ ) relative to gestational age (weeks) for mitral value and tricuspid valve with individual and mean (SD) standard deviation score (SDS)

\begin{tabular}{|c|c|c|c|c|c|c|}
\hline \multirow[b]{3}{*}{$\begin{array}{l}\text { Gestational } \\
\text { age (weeks) }\end{array}$} & \multicolumn{3}{|c|}{ Mitral valve } & \multicolumn{3}{|c|}{ Tricuspid valve } \\
\hline & \multicolumn{2}{|c|}{ Time-averaged velocity } & \multirow[b]{2}{*}{$S D S$} & \multicolumn{2}{|c|}{ Time-averaged velocity } & \multirow[b]{2}{*}{$S D S$} \\
\hline & Mean & $\begin{array}{c}\text { Reference } \\
\text { mean }(S D)\end{array}$ & & Mean & $\begin{array}{l}\text { Reference } \\
\text { mean }(S D)\end{array}$ & \\
\hline 27.0 & 14.1 & $17.8(1.1)$ & -3.36 & 15.8 & $19.7(1.5)$ & -2.60 \\
\hline 29.4 & 16.8 & $18.6(1.4)$ & -1.29 & 17.4 & $20.5(1.6)$ & -1.94 \\
\hline 31.5 & 16.5 & $19.2(1.5)$ & -1.80 & 16.1 & $21.2(1.7)$ & -3.00 \\
\hline 33.0 & 14.4 & $19.6(1.6)$ & -3.25 & 15.5 & $21.7(1.8)$ & -3.44 \\
\hline 34.0 & 16.1 & $19.9(1.7)$ & -2.24 & 15.1 & $22.0(1.8)$ & -3.83 \\
\hline 34.2 & 18.6 & $20.0(1.7)$ & -0.82 & 19.0 & $22.1(1.9)$ & -1.72 \\
\hline 35.2 & 17.3 & $20.3(1.8)$ & -1.67 & 15.6 & $22.4(1.9)$ & -3.58 \\
\hline 35.4 & 16.8 & $20.4(1.8)$ & -2.00 & 17.8 & $22.5(1.9)$ & -2.47 \\
\hline 36.0 & 14.6 & $20.5(1.9)$ & -3.28 & 15.7 & $22.7(2.0)$ & -3.50 \\
\hline 37.4 & 17.8 & $21.0(2.0)$ & -1.78 & 16.8 & $23.2(2.1)$ & -3.05 \\
\hline 38.0 & 17.3 & $21.1(2.0)$ & -2.00 & 20.3 & $23.3(2.1)$ & -1.38 \\
\hline 38.3 & 16.5 & $21.2(2.1)$ & -2.35 & 17.4 & $23.5(2.1)$ & -2.90 \\
\hline
\end{tabular}

Mean SDS (SD): $-2.15(0.80)^{*}$; mean SDS (SD): $-2.78(0.78)^{*}$

${ }^{*} p<0.001$

Table 5 Mean time-averaged velocity $(\mathrm{cm} / \mathrm{s})$ in blocked supraventricular extrasystoles (Group 2) and normal control values (mean $\pm 1 \mathrm{SD}$ ) relative to gestational age (weeks) for pulmonary artery and ascending aorta with individual and mean (SD) standard deviation score (SDS)

\begin{tabular}{|c|c|c|c|c|c|c|}
\hline \multirow[b]{3}{*}{$\begin{array}{l}\text { Gestational } \\
\text { age (weeks) }\end{array}$} & \multicolumn{3}{|c|}{ Pulmonary artery } & \multicolumn{3}{|c|}{ Ascending aorta } \\
\hline & \multicolumn{2}{|c|}{ Time-averaged velocity } & \multirow[b]{2}{*}{$S D S$} & \multicolumn{2}{|c|}{ Time-averaged velocily } & \multirow[b]{2}{*}{$S D S$} \\
\hline & Mean & $\begin{array}{l}\text { Reference } \\
\text { mean }(S D)\end{array}$ & & Mean & $\begin{array}{l}\text { Reference } \\
\text { mean (SD) }\end{array}$ & \\
\hline 25.3 & 13.2 & $21.8(1.7)$ & -5.06 & 15.7 & $25.9(2.0)$ & -5.10 \\
\hline 27.4 & 17.6 & $22.9(1.7)$ & -3.12 & 16.5 & $26.9(2.2)$ & -4.73 \\
\hline 28.0 & 17.0 & $23.1(1.7)$ & -3.59 & 18.5 & $27.1(2.3)$ & -3.74 \\
\hline 30.2 & 18.7 & $24.3(1.9)$ & -2.95 & 21.9 & $28.1(2.5)$ & -2.48 \\
\hline 30.3 & 16.4 & $24.4(1.9)$ & -4.21 & 17.8 & $28.2(2.5)$ & -4.16 \\
\hline 34.2 & 17.9 & $26.5(2.1)$ & -4.10 & 16.7 & $30.0(3.0)$ & -4.43 \\
\hline 36.0 & 15.8 & $27.4(2.3)$ & -5.04 & 18.3 & $30.7(3.2)$ & -3.88 \\
\hline
\end{tabular}

Mean SDS (SD): $-4.01(0.85)^{*}$; mean SDS (SD): $-4.07(0.85)^{*}$

${ }^{*} p<0.001$

186 Ultrasound in Obstetrics and Gynccology 
Table 6 Mean time-averaged velocity $(\mathrm{cm} / \mathrm{s})$ in blocked supraventricular extrasystoles (Group 2) and normal control values (mean $\perp$ 1SD) relative to gestational age (weeks) for mitral valve and tricuspid valve with individual and mean (SD) standard deviation score (SDS)

\begin{tabular}{|c|c|c|c|c|c|c|}
\hline \multirow[b]{3}{*}{$\begin{array}{l}\text { Gestational } \\
\text { age (weeks) }\end{array}$} & \multicolumn{3}{|c|}{ Mitral valve } & \multicolumn{3}{|c|}{ Tricuspid valve } \\
\hline & \multicolumn{2}{|c|}{ Time-averaged velocity } & \multirow[b]{2}{*}{$S D S$} & \multicolumn{2}{|c|}{ Time-averaged velocity } & \multirow[b]{2}{*}{$S D S$} \\
\hline & Mean & $\begin{array}{l}\text { Reference } \\
\text { mean }(S D)\end{array}$ & & Mean & $\begin{array}{c}\text { Reference } \\
\text { mean }(S D)\end{array}$ & \\
\hline 25.3 & 13.8 & $17.3(1.3)$ & 2.69 & 16.7 & $19.1(1.5)$ & -1.60 \\
\hline 27.4 & 16.4 & $18.0(1.3)$ & -1.23 & 17.7 & $19.9(1.5)$ & -2.80 \\
\hline 28.0 & 13.2 & $18.1(1.3)$ & -3.77 & 15.9 & $20.0(1.6)$ & -2.56 \\
\hline 30.2 & 19.1 & $18.8(1.5)$ & 0.20 & 18.9 & $20.8(1.7)$ & -2.29 \\
\hline 30.3 & 15.1 & $18.8(1.5)$ & -2.47 & 15.4 & $20.8(1.7)$ & -3.18 \\
\hline 34.2 & 15.6 & $20.0(1.7)$ & -2.60 & 18.8 & $22.1(1.9)$ & -2.14 \\
\hline 36.0 & 14.4 & $20.5(1.9)$ & -3.21 & 16.0 & $22.7(2.0)$ & -3.35 \\
\hline
\end{tabular}

Mean SDS (SD): $-2.25(1.33)^{*} ;$ mean SDS (SD): $-2.41(0.67)^{\dagger}$

${ }^{*} p<0.001 ;{ }^{\dagger} p<0.002$

Table 7 Slopes for the regression lines from peak systolic velocities $(\mathrm{cm} / \mathrm{s})$ for extrasystolic, normal and post-extrasystolic beats with filling time (ms) in pulmonary artery and ascending aorta in conductcd supraventricular extrasystoles (Group 1)

\begin{tabular}{lcc}
\hline \multirow{2}{*}{$\begin{array}{l}\text { Gestational age } \\
\text { (weeks) }\end{array}$} & \multicolumn{2}{c}{ Slope } \\
\cline { 2 - 3 } & Pulmonary artery & Ascending aorta \\
\hline 27.0 & 0.25 & 0.25 \\
29.4 & 0.13 & 0.11 \\
31.5 & 0.14 & 0.09 \\
33.0 & 0.16 & 0.47 \\
34.0 & 0.34 & 0.15 \\
34.2 & 0.16 & 0.12 \\
35.2 & 0.33 & 0.42 \\
35.4 & 0.19 & 0.22 \\
36.0 & 0.15 & 0.15 \\
37.4 & 0.12 & 0.07 \\
38.0 & 0.11 & 0.20 \\
38.3 & 0.17 & 0.68 \\
\hline
\end{tabular}

Mean slope (SD): $0.19(0.08)^{*} ; 0.24(0.19)^{\dagger}$

${ }^{*} p<0.001 ;{ }^{\dagger} p<0.002$

in situations where the beat-to-beat interval transiently changes, as in the presence of extrasystolic beats ${ }^{9,10}$. It was noted that the extrasystolic contraction, occurring prematurely in the cardiac cycle, is weak, and that the post-extrasystolic beat, which is delayed, is potentiated. These observations can in part be attributed to hemodynamic mechanisms, because the weak beat occurs after a shorter than usual filling time (lower preload) and meets a higher aortic pressure (higher afterload), whereas the potentiated beat is preceded by a longer than normal time interval (higher preload) and cjects against a lower aortic pressure (lower afterload). However, several observations show that this is not the major responsible mechanism; an enhanced inotropic state independent of changes in preload and afterload has been found to occur in the first post-extrasystolic beat ${ }^{9}$.

The 19 fetuses studied in this series were all otherwise normal and supraventricular extrasystoles disappeared either in the course of pregnancy or shortly after birth. In these circumstances, supraventricular extrasystolic beats can be considered as a model for the study of fetal cardiac activity in which a disturbance of the regular fetal heart rate gives varying ventricular end-diastolic filling volume and afterload.

$\Lambda t$ semilunar level, statistical analysis was performed for peak systolic velocity and acceleration time. The former reflects stroke volume" , the latter is mainly determined by afterload ${ }^{12}$. The peak systolic velocity for the first post-extrasystolic beat was always higher than for normal heats, probably reflecting the combined effects from post-extrasystolic potentiation, the FrankStarling mechanism and decreased afterload. Accordingly, the peak systolic velocity for extrasystolic beats was always lower than for normal beats. Both animal laboratory experiments and human fetal Doppler studies do indeed suggest that the Frank-Starling mechanism is operative and cffective in the fetal heart ${ }^{13}$. In the range of normal human fetal heart rates, changes in cardiac output appear to be mainly determined by heart rate, since in this range the myocardium is functioning at the plateau of the Frank-Starling curve ${ }^{16.17}$. At lower heart rates, the Frank-Starling mechanism compensates for changes in preload, thus keeping cardiac output constant while ventricular end-diastolic filling volumes change. At heart rates higher than 250 beats/min and lower than 50 beats $/ \mathrm{min}$, this mechanism begins to fail ${ }^{18}$. In our series, it was noted that fetal heart rate following an extrasystole never fell below 80 beats $/ \mathrm{min}$, so that the functional limit of the Frank-Starling mechanism was not reached. Furthcrmore, cvidence has been found for the cxistence of a force-interval relationship in the fetal heart. Studies in the fetal sheep ${ }^{19}$ showed the presence of a positive inotropic effect with increasing contraction frequency (post-stimulation potentiation) up to a heart rate of about 270 beats $/ \mathrm{min}$; at higher heart rates, relaxation of the ventricle became incomplete due to inadequate time for ventricular filling and/or diminished coronary blood flow. Electrocardiographic analysis of a case of human fetal extrasystoles ${ }^{20}$ demonstrated that fetal cardiac post-extrasystolic potentiation was indeed taking place, and that this was due in part to inotropic potentiation of the post-extrasystolic beats. 
In our study, acceleration time was always increased in post-extrasystolic beats. It has been shown that acceleration time is inversely related to intra-arterial pressure $^{12}$; therefore, this finding may reflect reduced afterload during a post-extrasystolic beat. The acceleration time for extrasystoles was lower than for normal beats.

At atrioventricular level, the peak-E wave velocity remained unchanged during post-extrasystolic beats in all women, while the peak-A wave velocity fell and the $\mathrm{E} / \mathrm{A}$ ratio increased. The increase in $\mathrm{E} / \mathrm{A}$ ratio can be explained by a lower afterload during post-extrasystolic beats ${ }^{8}$. The altered preceding time interval may also have influenced the timing and course of ventricular relaxation $^{9}$. The fall-off of peak-A wave velocity could be related to the prolonged preceding time interval. We found, in an earlier study on normal cardiac flow velocity waveforms, that the peak- $E$ wave velocity increases with decrcasing hcart ratc, whilst the peak-A wave velocity decreases $^{8}$. Our observation of an unchanged pcak-E wave velocity during post-extrasystolic beats seems to be in contradiction with these normal findings.

Previously, an inverse relationship has been found to exist between the extrasystolic filling time and the amount of potentiation. Also, post-extrasystolic potentiation appears to decay gradually over some beats ${ }^{9,10}$. However, in this study we found no evidence of decay of post-extrasystolic potentiation following a postextrasystolic beat, nor were we able to establish a relationship between the extrasystolic filling time and the peak systolic velocity for the post-extrasystolic beats, or between peak systolic velocities for extrasystolic, normal and post-extrasystolic beats scparatcly with filling timc.

These last figures should, however, be interpreted in combination with another result from this study. There was a marked decrease of the time-averaged velocity during supraventricular extrasystoles at all four measuring sites compared with reference values. We suggest that, during a post-extrasystolic beat, due to increased blood volume plus increased pressure at ventricular level, valve areas may become larger. The increased ventricular ejection force probably does not counterbalance this effect. This would result in relatively lower peak systolic and time-averaged velocities during a post-extrasystolic beat, giving rise to an underestimation of fetal blood flow if time-averaged velocity werc considered as a measure of flow. Other authors have already suggested the possibility that fetal cardiac valve areas may change ${ }^{21}$, and we found evidence for this suggestion in an earlier study on normal blood flow velocity waveforms at fetal cardiac level. Here, a negative correlation of the atrioventricular time-averaged velocity with the period time was calculated $^{8}$.

This underestimation of the peak systolic velocity in potentiated beats may have confused some of our results. We were not able to establish a decay of post-extrasystolic potentiation following a post-extrasystolic beat or an inverse relationship between extrasystolic filling time and peak systolic velocity of the post-extrasystolic beat. It might also explain the constancy of the peak-E wave velocity and the decrease of the peak-A wave velocity during a post-extrasystolic beat. However, the velocity differences concerned may be such that we could not detect them by Doppler ultrasound, since they may have been smaller than the intra-observer variability established in our Department for these parameters; for pcak systolic velocity, the coefficients of variation between tests within patients were $<7 \%$ at outflow tract level and $<4 \%$ at atrioventricular level.

The regression coefficient for peak systolic velocities from extrasystolic, normal and post-extrasystolic beats with filling time was significant for both the pulmonary artery and the ascending aorta. This also seems to represent the combined effect of hemodynamic factors and post-extrasystolic potentiation at a ventricular level. Between peak systolic velocities for extrasystolic, normal and post-extrasystolic beats separately, no relationship could be established with filling time, although this is likely to exist. This discrepancy may also be attributed to either changing valve areas or intra-observer variability.

In conclusion, Doppler examination of the human fetal heart during supraventricular extrasystolic beats indicates that the Frank-Starling mechanism and postextrasystolic potentiation do exist in the fetal heart, although the relative contributions from both mechanisms cannot be determined in this way. During supraventricular extrasystoles, the limits of the Frank-Starling mechanism are not reached, supporting the theory that extrasystoles do not have hemodynamic consequences. Further, the suggestion is made that, during an increase in blood volume and/or force of contraction, cardiac valve arcas may become larger, thus giving rise to an underestimation of fetal blood flow mcasured by Doppler ultrasound when peak systolic velocity or time-averaged velocity is considered. Therefore, cardiac Doppler data should be interpreted with caution when beat-tobeat intervals change rapidly.

\section{ACKNOWLEDGEMENT}

I wish to thank Dr P. A. Stewart for performing the M-mode echocardiograms

\section{REFERENCES}

1. Allan, L. D., Anderson, R. H., Sullivan, I. D., Campbell, S., Holt, D. W. and Tynan, M. (1983). Evaluation of fetal arrhythmias by echocardiography. Br. Heart J., 50, 240-5

2. Lingman, G., Lundstrom, N. R., Marsal, K. and (Ohrlander, S. (1986). Fetal cardiac arrhythmia. Acta Obstet. Gynaecol. Scand., 65, 263-7

3. Stewart, P. A. (1989). Echocardiography in the human fetus. Thesis, Erasmus University Rotterdam, The Netherlands

4. Redman, T. F. (1958). The significance of some unusual foetal cardiac arrhythmias. J. Obstet. Gynaecol. Br. Emp., 65, 304-9

5. Southall, D. P., Richards, J., Hardwick, R. A., Shinebourne, E. A., Gibbens, G. I. D., Thelwall-Iones, H., De Swiet, M. and Johnston, P. G. B. (1980). Prospective sludy 
of fetal heart rate and rhythm patterns. Arch. Dis. Child., 55, 506-11

6. Wladimiroff, I. W., Huisman, T. W. A. and Stewart, P. A. (1991). Fetal cardiac flow velocities in the late 1st trimester of pregnancy: a transvaginal Doppler study. JACC, 17, $1357-9$

7. Kloosterman, G. J. (1970). On intrautcrinc growth. Int. J. Gynaecol. Obstet., 8, 895-913

8. Van der Mooren, K., Barendregt, L. G. and Wladimiroff, J. W. (1991). Fetal atrioventricular and outflow tract flow velocity waveforms during the normal second half of pregnancy. Am. J. Obstet. Gynecol., 165, 668-74

9. Seed, W. A. and Walker, J. M. (1988). Relation between beat interval and force of the heartbeat and its clinical implications. Cardiovasc. Res., 22, 303-14

10. Wisenbaugh, T., Nissen, S. and DeMaria, A. (1986). Mechanics of postextrasystolic potentiation in normal subjects and patients with valvular heart disease. Circulation, 1, $10-20$

11. Hatle, L. and Angelsen, B. A. J. (1981). Doppler Ultrasound in Cardiology: Physical Principles and Clinical Application, pp. 206-10. (Trondheim: SINTEF)

12. Machado, M. V. L., Chita, S. C. and Allan, L. D. (1987). Acceleration time in the aorta and pulmonary artery mcasurcd by Doppler cchocardiography in the midtrimester normal human fetus. Rr. Heart .J., 58, 15-18

13. Kirkpatrick, S. E., Pillick, P. T., Naliboff, J. and Friedman, W. F. (1987). Frank-Starling relationship as an important determinant of fetal cardiac output. Am. J. Phys., 231 , $495-500$
14. Marsal, K., Lindblad, A. and Lingman, G. (1984). Blood flow in the fetal descending aorta; intrinsic factors affecting fetal arrhythmia. Ultrasound Med. Biol., 10, 339-48

15. Reed, K. L., Sahn, D. J., Marx, G. R., Anderson, C. F. and Shenker, L. (1987). Cardiac Doppler flows during fetal arrhythmias: physiological consequences. Obstet. Gynecol., 70, $1-6$

16. Gilbert, R. D. (1980). Control of fetal cardiac output during changes in blood volume. Am. J. Phys., 238, H80-6

17. Tonge, H. M., Wladimiroff, J. W., Noordam, M. J. and Stewart, P. A. (1986). Fetal cardiac arrhythmias and their cffect on volume blood flow in descending aorta of human fetus. J. Clin. Ultrasound, 14, 607-12

18. Tonge, H. M., Stewart, P. A. and Wladimiroff, J. W. (1984). Fetal blood flow measurements during fetal cardiac arrhythmia. Early Hum. Dev., 10, 23-34

19. Kirkpatrick, S. E., Naliboff, J., Pitlick, P. T. and Friedman, W. F. (1975). Influence of poststimulation potentiation and heart rate on the fetal lamb. Am. J. Phys., 229, 318-23

20. Smith, G. C. S., Fleming, J. E. E. and Whitfield, C. R. (1990). Post-extrasystolic potentiation in a human fetus detected during measurement of systolic time intcrvals in labour. Eur. J. Obstet. Reprod. Biol., 37, 205-10

21. Kenny, J., Plappert, T., Doubilet, P., Salzman, D. and John Sutton, M. G. (1987). Effects of heart rate on ventricular size, stroke volume, and output in the normal human fetus: a prospective Doppler echocardiographic study. Circulation, 76, 52-8 